\title{
A Method to Identify Synoptically Undisturbed, Clear-Sky Conditions for Valley-Wind Analysis
}

\author{
Manuela Lehner $^{1}$ (D) $\cdot$ Mathias W. Rotach ${ }^{1} \cdot$ Friedrich Obleitner $^{1}$ \\ Received: 21 January 2019 / Accepted: 25 July 2019 / Published online: 12 August 2019 \\ (c) The Author(s) 2019
}

\begin{abstract}
"Valley-wind days" are characterized by synoptically undisturbed, clear-sky conditions, which lead to the formation of thermally-driven slope- and valley-wind circulations in mountain regions. A simple method is presented to identify these conditions in the Inn Valley, Austria, using ERA-Interim geopotential height fields and a clear-sky index, which is calculated from measurements of longwave incoming radiation, air temperature, and humidity at a single site on the valley floor. As the method is based on identifying weak synoptic-scale flows and clear skies, it can also be applied to the identification of ideal conditions for other thermally-driven circulations. The mean diurnal cycle of the valley-wind circulation on these days is briefly discussed.
\end{abstract}

Keywords Clear-sky index · Thermally-driven flows · Valley winds · Weak synoptic forcing

\section{Introduction}

Regional, thermally-driven circulations can dominate the wind field in the atmospheric boundary layer during synoptically undisturbed, clear-sky conditions. An example is the diurnal slope- and valley-wind system in mountain valleys, which forms as a result of horizontal temperature gradients (Zardi and Whiteman 2012). During daytime, the near-surface air along slopes warms more than the air away from the slope. The resulting buoyancy produces an upslope flow along the sidewall, while stronger cooling at night-time produces a downslope flow. Valley winds, on the other hand, form as a result of horizontal temperature differences between the valley atmosphere and the adjacent plain due to stronger heating of the valley during daytime and stronger cooling during night-time, which leads to horizontal pressure gradients (Vergeiner and Dreiseitl 1987). Both slope winds and valley winds are thus typically characterized by a twice daily reversal of the flow direction, with the transition from night-time downslope to daytime upslope winds in the morning and vice versa in the evening occurring almost immediately after sunrise and sunset, respectively. The valley-wind transition lags the slope-wind transition, with the valley-wind transition oftentimes occurring

Manuela Lehner

manuela.lehner@uibk.ac.at

1 Department of Atmospheric and Cryospheric Sciences, University of Innsbruck, Innrain 52f, 6020 Innsbruck, Austria 
several hours after sunrise or sunset, depending on the size of the valley and thus the volume of the valley atmosphere (Zardi and Whiteman 2012). Valley and slope winds are typically characterized by a jet-like profile, with night-time down-valley flows having a wind-speed maximum several tens to hundreds of metres above the ground, whereas the daytime profiles are typically somewhat better mixed (Zardi and Whiteman 2012). Valley winds play an important role in the transport of energy and mass, including air pollutants in the mountain boundary layer (Lehner and Rotach 2018).

To study boundary-layer processes and characteristics, it is often useful to distinguish between entirely thermally-driven mesoscale flow conditions and largely dynamically-driven (e.g., foehn) and synoptically-driven conditions, for example, to evaluate the performance of model parametrizations during valley flow (Goger et al. 2018). A large number of studies thus deal with the description and analysis of thermally-driven flows in complex terrain under undisturbed conditions (e.g., Zardi and Whiteman 2012), so-called valley-wind days (VWDs), as well as their effect on the atmospheric boundary layer (e.g., Lehner and Rotach 2018; Serafin et al. 2018). When working with large datasets rather than individual case studies, it can thus become necessary to automatically identify VWDs.

Dreiseitl et al. (1980) and Vergeiner and Dreiseitl (1987) determined VWDs in the Inn Valley, Austria, based on an identification of twice-daily transitions in wind direction, that is, from down-valley to up-valley and vice versa during predefined time windows in the morning and evening, respectively. An alternative is to use other parameters to identify the conditions leading to VWDs or a combination of wind direction and other parameters. Giovannini et al. (2017), for example, identified VWDs for the Adige Valley, Italy, using daily integrals of global solar radiation, thresholds for daily pressure ranges, and a requirement for persistent up-valley and down-valley flows during daytime and night-time, respectively, while Matzinger et al. (2003) used only cloud cover to identify valley-wind days. Martínez et al. (2008) and Conangla et al. (2018) used criteria to identify clear-sky, undisturbed conditions, specifically, stable nights. They also compared the observed daily solar irradiation with the theoretical irradiation at the top of the atmosphere, used a threshold value for the observed nocturnal wind speed, and a humidity criterion to identify dry conditions.

Here, we present a method to identify synoptically undisturbed, clear-sky days using the example of the Inn Valley based on geopotential-height gradients in ERA-Interim reanalysis data and a clear-sky index (CSI; Marty and Philipona 2000). The identified days are expected to be determined by the thermally-driven slope- and valley-wind system and are thus termed VWDs. Local wind data are not considered in the identification of VWDs, but diurnal cycles of wind speed and direction presented in Sect. 3 show the characteristic development of a valley-wind circulation and its relation to the local along-valley pressure gradient on the identified VWDs.

The Inn Valley is an approximately south-west-north-east oriented valley in the western part of Austria, with a depth of about $2000 \mathrm{~m}$ and a width of about $2 \mathrm{~km}$ in the vicinity of the measurement site. Four years (2014-2017) of half-hourly data are used from a 17-m high turbulence tower, which is part of the i-Box project (Innsbruck Box; Rotach et al. 2017) and which is located approximately in the centre of the valley floor $\left(47.305^{\circ} \mathrm{N}, 11.622^{\circ} \mathrm{E}, 545 \mathrm{~m}\right.$ above mean sea level). Following Rotach et al. (2017), the site is referred to as the VF0 site (valley floor, $0^{\circ}$ slope angle). Longwave and shortwave radiation data are based on measurements from ventilated CGR4 pyrgeometers and CMP21 pyranometers, respectively (Kipp \& Zonen, Delft, The Netherlands), wind direction from a CSAT3 sonic anemometer (Campbell Scientific, Logan, Utah, USA), and temperature and humidity from a PT100 sensor and HT-1 hygrometer (HC2A-S, Rotronic, Bessersdorf, Switzerland), respectively. Turbulent sensible and latent heat fluxes for the surface energy balance were calculated from measurements with 
the sonic anemometer and a co-located infrared gas analyzer (EC150, Campbell Scientific, Logan, Utah, USA). Temperature and humidity are measured at $17 \mathrm{~m}$ above ground level (a.g.l.); the sonic anemometer and infrared gas analyzer were installed at $4 \mathrm{~m}$ a.g.l., and radiation measurements are made at $2 \mathrm{~m}$ a.g.l. Ground-heat-flux calculations are based on measurements using a soil heat-flux plate (HFP01, Hukseflux, Delft, The Netherlands) at $0.1 \mathrm{~m}$ and soil temperature and moisture measurements approximately $0.05 \mathrm{~m}$ farther above (TRIME-PICO, IMKO, Ettlingen, Germany).

\section{Identification of Valley-Wind Days}

To identify VWDs, two criteria are combined: (i) a criterion to identify synoptically undisturbed days, that is, days with a weak large-scale pressure gradient, and (ii) a criterion to identify clear-sky days based on a clear-sky index (Marty and Philipona 2000). Both criteria have to be met to classify a given day as a VWD.

\subsection{Synoptically Undisturbed Days}

Synoptically undisturbed days are identified from ERA-Interim (Dee et al. 2011) geopotentialheight gradients at the 700-hPa surface, which is located about $500 \mathrm{~m}$ above the average ridge level in the vicinity of the Inn Valley. Gradients are calculated for 0000 and 1200 UTC in both west-east (i.e., $\Delta Z / \Delta x$ ) and south-north (i.e., $\Delta Z / \Delta y$ ) directions across $2 \Delta x$ (between $12.0^{\circ} \mathrm{E}, 48.0^{\circ} \mathrm{N}$ and $12.0^{\circ} \mathrm{E}, 46.5^{\circ} \mathrm{N}$ ) and $2 \Delta y$ (between $12.75^{\circ} \mathrm{E}, 47.25^{\circ} \mathrm{N}$ and $\left.11.25^{\circ} \mathrm{E}, 47.25^{\circ} \mathrm{N}\right)$, respectively, with the VF0 site approximately centred in-between. A threshold value for weak gradients is then applied to both $\Delta Z / \Delta x$ and $\Delta Z / \Delta y$. Holton and Hakim (2013) define the magnitude of a typical midlatitude synoptic cyclone with $\delta p / L=10^{-3} \mathrm{~Pa} \mathrm{~m}^{-1}$, where $\delta p=10^{3} \mathrm{~Pa}$ is a typical pressure disturbance and $L=1000 \mathrm{~km}$ is the horizontal scale. This typical pressure gradient corresponds to a geopotential height $Z$ gradient of $\delta Z / L=\delta p / g L=10^{-4}$.

Requiring that both $|\Delta Z / \Delta x|$ and $|\Delta Z / \Delta y|$ are at least one order of magnitude smaller than the threshold of $10^{-4}$ for a typical cyclone given by Holton and Hakim (2013) leaves only $1.7 \%$ of all 0000 and 1200 UTC data points between 2014 and 2017. Based on the frequency distributions of $\Delta Z / \Delta x$ and $\Delta Z / \Delta y$ in Fig. 1 and using the value of Holton and Hakim (2013) as a guideline, a slightly more relaxed threshold of $4 \times 10^{-5}$ was selected to identify synoptically undisturbed conditions so that at least $25 \%$ of all cases are selected. Specifically, 28\% of all 0000 and 1200 UTC geopotential height fields meet this criterion during 2014-2017. To summarize, a day is identified as a synoptically undisturbed day if both $\Delta Z / \Delta x$ and $\Delta Z / \Delta y$ are less than or equal to $4 \times 10^{-5}$ at 0000 and 1200 UTC and at 0000 UTC of the following day, which yields a total of 188 synoptically undisturbed days during the four years. ERA-Interim reanalysis has a resolution of $0.75^{\circ}$. Tests with the more highly resolved ERA5 dataset suggest that as more details of the circulation are resolved and the fields thus become less smooth, either the threshold needs to be relaxed or averages over multiple grid points need to be used, particularly if the gradients are evaluated over comparatively smaller distances. 


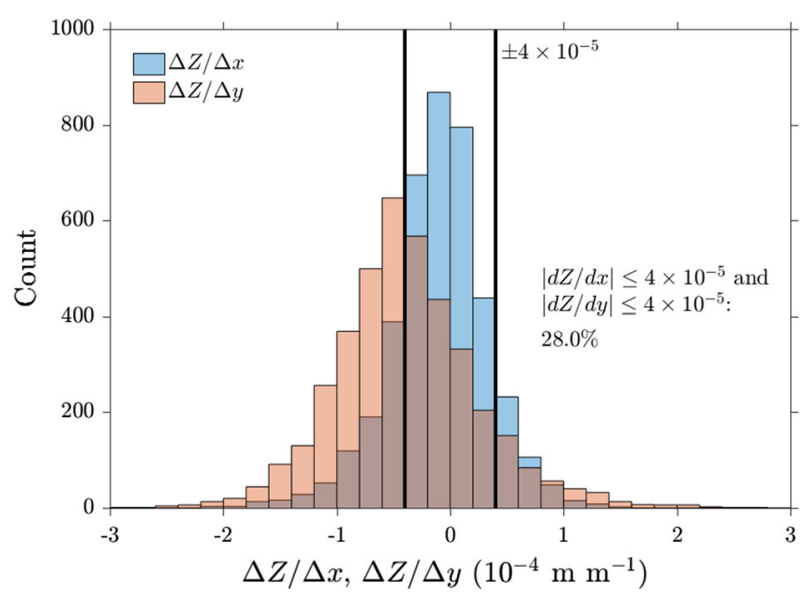

Fig. 1 Distributions of $\Delta Z / \Delta x$ and $\Delta Z / \Delta y$ for 0000 and 1200 UTC between 2014 and 2017, with a bin width of $0.2 \times 10^{-4}$

\subsection{Clear-Sky Days}

Clear-sky conditions are identified using a clear-sky index (Marty and Philipona 2000)

$$
C S I=\frac{\epsilon_{A}}{\epsilon},
$$

where $\epsilon$ is the modelled atmospheric emissivity for clear-sky conditions and $\epsilon_{A}$ is the actual atmospheric emissivity calculated from measurements

$$
\epsilon_{A}=\frac{L_{\downarrow}}{\sigma T^{4}},
$$

with $L_{\downarrow}$ being the measured longwave incoming radiation, $T$ the observed air temperature, and $\sigma=5.67 \times 10^{-8} \mathrm{~W} \mathrm{~m}^{-2} \mathrm{~K}^{-4}$ is the Stefan-Boltzmann constant. To exclude times with snow cover or frost on the radiometer from the analysis, the albedo was calculated from shortwave radiation measurements and the data were excluded if the albedo $>0.9$. The sky is considered clear if $C S I \leq 1$, that is, if the actual atmospheric emissivity $\epsilon_{A}$ is less than or equal to the modelled atmospheric emissivity for clear-sky conditions $\epsilon$. In contrast to clear-sky identification methods based on solar radiation, the CSI method has the advantage that it is based on longwave radiation and thus is also applicable during night-time.

Atmospheric emissivity $\epsilon_{A}$ is calculated from 30-min averages of 1-min observations of temperature (17 $\mathrm{m}$ a.g.1.) and longwave incoming radiation $(2 \mathrm{~m}$ a.g.l.) at the VF0 site. A large number of models exists for the clear-sky emissivity $\epsilon$, which typically parametrize $\epsilon$ as a function of air temperature $T$ and water vapour pressure $e$ (see, e.g., Prata (1996) and Niemelä et al. (2001) for reviews). The models are generally based on fits of $\epsilon_{A}$ for clear-sky conditions at different sites around the world. Several of these models were tested here to identify the one that provides the best fit to the data from the VF0 site (Table 1).

Histograms of atmospheric emissivity $\epsilon_{A}$ calculated from observations and parametrized emissivity $\epsilon$ are shown in Fig. 2. Since there are no sky observations or automatic all-sky images available for the VF0 site, there is no direct way of identifying clear-sky data points. The histograms in Fig. 2, however, reveal two main clusters. The first cluster with low $\epsilon_{A}$ around 0.8 can be assumed to represent clear-sky conditions and the second cluster with high 
Table 1 List of models for clear-sky atmospheric emissivity, where $T$ and $e$ are air temperature in $\mathrm{K}$ and water vapour pressure in $\mathrm{hPa}$, respectively. Coefficients in MP00 are those listed for Payerne, Switzerland

\begin{tabular}{lll}
\hline Reference & Abbrev. & Function \\
\hline Brutsaert (1975) & B75 & $\epsilon=1.24(e / T)^{1 / 7}$ \\
Prata (1996) & P96 & $\epsilon=1-(1+46.5 e / T) \exp \left[-(1.2+139.5 e / T)^{1 / 2}\right]$ \\
Dilley and O'Brien (1998) & DO98 & $\epsilon=\left[59.38+113.7(T / 273.16)^{6}+96.96 \sqrt{465 / 25 e / T}\right] /\left(\sigma T^{4}\right)$ \\
Marty and Philipona (2000) & MP00 & $\epsilon=0.23+0.47(100 e / T)^{1 / 8}$ \\
Swinbank (1963) & S63 & $\epsilon=9.2 \times 10^{-6} T^{2}$ \\
Idso and Jackson (1969) & IJ69 & $\epsilon=1-0.261 \exp \left[-7.77 \times 10^{-4}(273-T)^{2}\right]$ \\
Ångström (1916) & A16 & $\epsilon=0.84-0.18 \times 10^{-0.067 e}$ \\
Satterlund (1979) & S79 & $\epsilon=1.08\left[1-\exp \left(-e^{T / 2016}\right)\right]$ \\
Idso (1981) & I81 & $\epsilon=0.7+5.95 \times 10^{-5} e \exp (1500 / T)$ \\
\hline
\end{tabular}
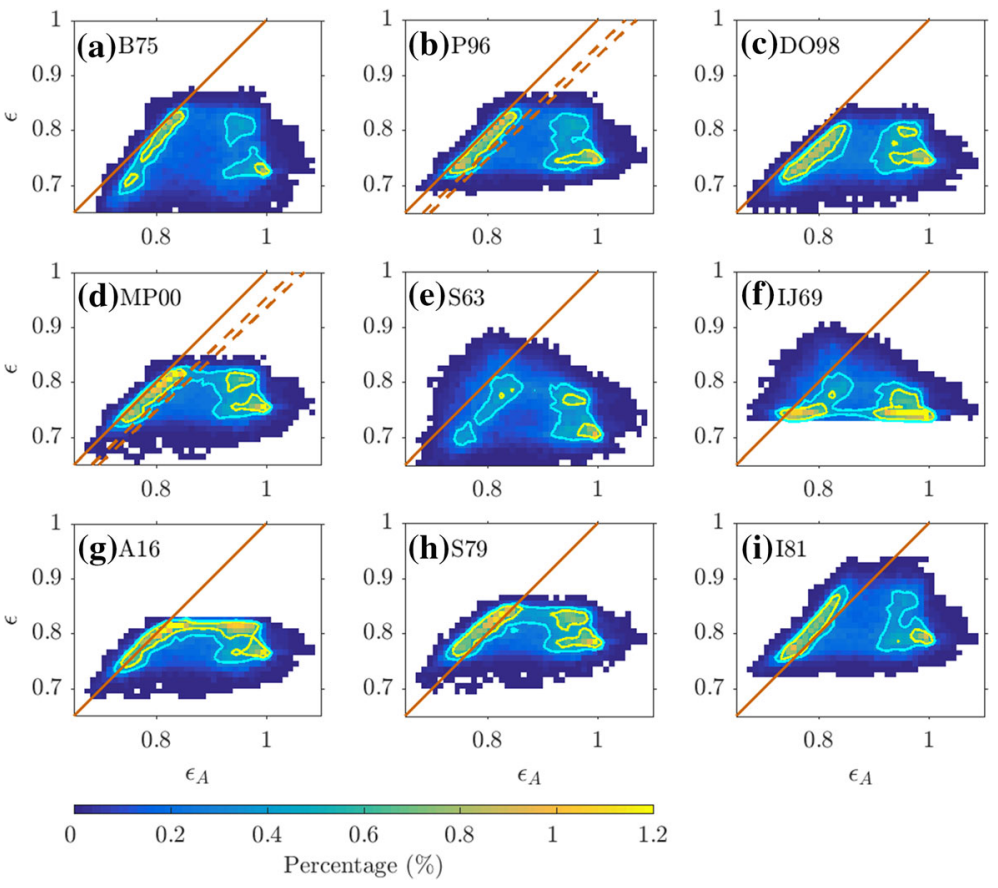

Fig. 2 Histograms of atmospheric emissivity and parametrized clear-sky emissivity for four years of data (2014-2017) at VF0. The different parametrizations for clear-sky emissivity are listed in Table 1, where the abbreviations are defined. Cyan and yellow contour lines highlight areas with percentages larger than 0.3 and $0.5 \%$, respectively. Red solid lines correspond to $C S I=\epsilon_{A} / \epsilon=1$ and red dashed lines in $\mathbf{b}$ and $\mathbf{d}$ correspond to $\epsilon_{A} / \epsilon=1 / 1.05$ and $1 / 1.07$ 
$\epsilon_{A}$ of close to 1 to represent cloudy conditions. There is, however, also a relatively large number of data points located between the two major data clusters, which cannot be clearly assigned to one of the two states.

For clear-sky conditions a close correspondence is expected between $\epsilon_{A}$ and $\epsilon$ calculated from the clear-sky parametrizations listed in Table 1, but no agreement for cloudy conditions. The two parametrizations that do not take humidity into account, that is, S63 and IJ69 (Fig. 2e, f), clearly perform the worst. This was also found by Sedlar and Hock (2009). The parametrizations that include a dependency on both temperature and humidity all show a more or less linear relation with observed values of $\epsilon_{A}$ for clear-sky conditions, but generally either underestimate (B75, P96, DO98, and MP00) or overestimate (S79 and I81) $\epsilon_{A}$. While the maxima related to clear-sky values in the histograms for P96 and MP00 remain relatively narrow and maintain a constant slope with $\epsilon_{A}$ over the entire range of clear-sky values (Fig. 2b, d), the maxima in the other histograms are slightly less homogeneous. Clear-sky emissivity based on B75, for example, agrees well with $\epsilon_{A}$ for values larger than about 0.8 , but starts to deviate for lower values. The parametrizations by A16 and I81, on the other hand, deviate somewhat more strongly at larger values of $\epsilon_{A}$.

With the assumption that the left peak in the histograms of Fig. 2 represents clear-sky conditions, we can look for a parametrization that best envelops these data. The red solid lines in Fig. 2 correspond to $\epsilon_{A}=\epsilon$ or $C S I=1$, that is, areas to the left of these lines would be identified as clear-sky conditions. It has to be noted again that there are no direct sky observations available and therefore no possibility of ranking the parametrizations entirely objectively. While the parametrizations by P96 and MP00 underestimate observed $\epsilon$, adding a constant multiplication factor to the parametrizations results in a relatively sharp differentiation of the clear-sky maximum in the histogram. These modified parametrizations are represented by the dashed red lines in Fig. 2. A comparison of the number of identified clear-sky days and VWDs between 2014 and 2017 using P96 and MP00 with different multiplication factors is given in Table 2. A clear-sky day is identified if the calculated CSI $\leq 1$ at the VF0 site for more than $90 \%$ of the 4830 -min averages during a day and finally, a VWD is identified if both criteria for synoptically undisturbed and clear-sky days are met. The parametrizations by MP00 and P96 give almost identical results. The magnitude of the multiplication factor, however, affects the results more strongly, with an increase in the factor from 1.05 to 1.07 leading to about 40-50 more clear-sky days in four years and about 10 more VWDs. The exact days identified by the two methods differ slightly, however, in that only $97.8 \%$ and $96.7 \%$ of the days identified by one of the two methods are simultaneously identified by the other method (Fig. 3).

Based on Fig. 2, we finally selected the criterion of Prata (1996) with a multiplication factor of $C=1.07$,

$$
\epsilon=C\left\{1-\left(1+46.5 \frac{e}{T}\right) \exp \left[-\left(1.2+139.5 \frac{e}{T}\right)^{1 / 2}\right]\right\},
$$

where $T$ is in $\mathrm{K}$ and $e$ in $\mathrm{hPa}$. This parametrization captures more or less the entire maximum in the histogram representing clear-sky conditions, that is, the area within the $0.3 \%$ isoline and yields a total of 182 clear-sky days between 2014 and 2017 (Table 2).

\subsection{Evaluation of the Clear-Sky Identification Method}

To evaluate the performance of the clear-sky identification algorithm, observed incoming shortwave radiation is compared to calculated extraterrestrial radiation (Fig. 4). The hypothe- 
Table 2 Number of identified clear-sky days and VWDs between 2014 and 2017 for different parametrizations of clear-sky emissivity. The parametrized $\epsilon$ values are multiplied by different factors to identify the subjectively best results for the VF0 site in the Inn Valley

\begin{tabular}{llcc}
\hline Parametrization & Multiplication factor & Clear-sky days & VWDs \\
\hline VF0 & & & \\
P96 & 1.05 & 134 & 42 \\
& 1.06 & 161 & 48 \\
& 1.07 & 182 & 54 \\
MP00 & 1.05 & 138 & 42 \\
& 1.06 & 163 & 47 \\
& 1.07 & 180 & 53 \\
Innsbruck (Ibk) & & & 57 \\
P96 & 1.07 & 199 & 4 \\
MP00 & 1.00 & 7 & 53 \\
MP00 & 1.07 & 192 & \\
\hline
\end{tabular}

\begin{tabular}{|c|c|c|c|c|c|c|c|c|c|}
\hline & P96 & MP00 & Ibk-P96 & Ibk-MP00 & $f_{c s}=80 \%$ & $f_{c s}=70 \%$ & $f_{c s}=60 \%$ & $4 \times 10^{-5}$ & $5 \times 10^{-5}$ \\
\hline P96 & 100.0 & 97.8 & 75.9 & 76.6 & 70.8 & 53.7 & 42.2 & 28.7 & 26.9 \\
\hline MP00 & 96.7 & 100.0 & 73.9 & 75.5 & 70.0 & 53.1 & 41.8 & 28.2 & 26.6 \\
\hline Ibk-P96 & 83.0 & 81.7 & 100.0 & 99.0 & 65.0 & 51.3 & 41.3 & 30.3 & 27.6 \\
\hline Ibk-MP00 & 80.8 & 80.6 & 95.5 & 100.0 & 62.6 & 49.3 & 39.7 & 28.2 & 25.6 \\
\hline$f_{c s}=80 \%$ & 100.0 & 100.0 & 83.9 & 83.9 & 100.0 & 75.8 & 59.6 & 37.8 & 34.9 \\
\hline$f_{c s}=70 \%$ & 100.0 & 100.0 & 87.4 & 87.0 & 100.0 & 100.0 & 78.7 & 45.7 & 42.5 \\
\hline$f_{c s}=60 \%$ & 100.0 & 100.0 & 89.4 & 89.1 & 100.0 & 100.0 & 100.0 & 53.7 & 48.8 \\
\hline $4 \times 10^{-5}$ & 29.7 & 29.4 & 28.6 & 27.6 & 27.6 & 25.4 & 23.4 & 100.0 & 62.5 \\
\hline $5 \times 10^{-5}$ & 44.5 & 44.4 & 41.7 & 40.1 & 40.9 & 37.8 & 34.1 & 100.0 & 100.0 \\
\hline & & & & & $\geq 0.0$ & $\geq 25.0$ & 40.0 & $\geq 80.0$ & 100.0 \\
\hline
\end{tabular}

Fig. 3 Comparison of days that are simultaneously identified by different methods. The number and background colour indicate the fraction of days identified by the method listed at the top that is also identified by the method listed on the left. For example, $97.8 \%$ of the days identified by MP00 are also identified by P96 as clear-sky days. Reversely, $96.7 \%$ of the days identified by P96 are also identified by MP00. Both P96 and MP00 refer to the parametrizations with a multiplication factor of 1.07. The numbers in the last two columns and rows refer to threshold values for the geopotential-height gradient 

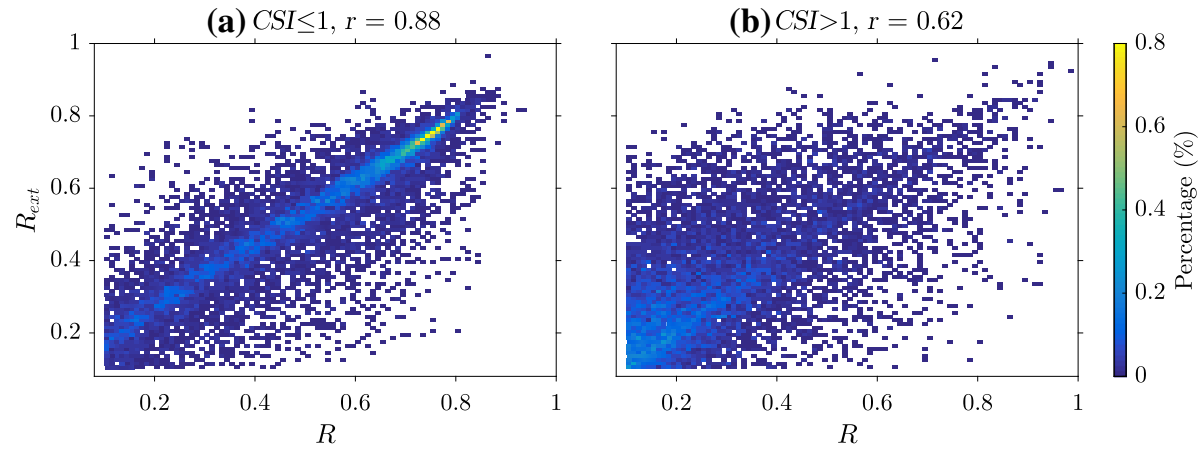

Fig. 4 Histograms of calculated extraterrestrial radiation $R_{\text {ext }}$ and observed incoming shortwave radiation $R$ for periods with $\mathbf{a} C S I \leq 1$ and $\mathbf{b} C S I>1$. Both $R_{\text {ext }}$ and $R$ are normalized by the maximum extraterrestrial radiation on a given day. Only data points with $R_{\text {ext }}$ and $R>0.1$ are shown and included in the calculation of the correlation coefficient

sis is that during clear-sky conditions, shortwave incoming radiation $R$ is strongly correlated with extraterrestrial radiation $R_{\text {ext }}$, but deviates during cloudy conditions. Extraterrestrial radiation $R_{e x t}$ was multiplied by a factor $C_{e x t}=R_{0} / R_{e x t, 0}$ to account for absorption in the atmosphere, where $R_{0}$ and $R_{\text {ext }, 0}$ are the observed incoming shortwave radiation and extraterrestrial radiation at the time of solar noon on a given day, respectively. In addition, both $R$ and $R_{\text {ext }}$ are normalized by $R_{\text {ext }, 0}$ and only daytime data are analyzed when both $R_{\text {ext }}$ and $R>0.1$. Figure 4a shows that most data points are located on the diagonal with a correlation coefficient of 0.88 , that is, most of the identified clear-sky data points are indeed non-cloudy. Conversely, the scatter is much larger in Fig. 4b, with a correlation coefficient of only 0.62 , indicating that there is correspondingly little correlation between $R$ and $R_{\text {ext }}$ as expected for cloudy periods. Using a more restrictive parametrization, for example, the original formulation of Prata (1996) increases the correlation between $R_{\text {ext }}$ and $R$ for clear-sky periods $(r=0.96)$ since it includes fewer cloudy periods, but also misses more clear-sky periods, as indicated by a higher correlation coefficient for $C S I>1(r=0.80)$. Therefore a compromise has to be found between missing as few clear-sky periods as possible and including as few cloudy periods as possible. The parametrization of Marty and Philipona (2000) performs almost identically to the parametrization of Prata (1996), resulting in the same correlation coefficients between $R$ and $R_{\text {ext }}$ when using the same multiplication factors.

Clear-sky emissivity depends on the altitude and climatic conditions. The parametrization for $\epsilon$ is thus site-dependent and the above results cannot be directly transferred to other locations. However, to test the universality of the selected parametrization (Eq. 3) within a given valley, we applied it to data from Innsbruck, approximately $20 \mathrm{~km}$ west of the VF0 site. The data were collected as part of the Austrian RADiation monitoring network (ARAD, Olefs et al. 2016) and it has to be noted that the radiation sensor was moved in mid 2016 from the urban centre of Innsbruck to the airport at the outskirts of the city. A slightly higher number of clear-sky days is identified for Innsbruck, with 199 compared to 182 days for VF0 (Table 2). Considering that $90 \%$ of the day has to be cloud-free to be classified as a clear-sky day means that many days with scattered, convective clouds are not identified as clear-sky days. A perfect agreement is thus not to be expected. This is also obvious from the number of simultaneously identified clear-sky days between sites VF0 (P96) and Innsbruck (Ibk-P96), with $83.0 \%$ and $75.9 \%$ depending on the reference site (Fig. 3). In combination with the criterion for synoptically undisturbed conditions (for the location of the VF0 site) 
Table 3 Number of identified clear-sky days, synoptically undisturbed days, and VWDs for different combinations of thresholds for the geopotential-height gradient $(\delta Z / L)$ and the fraction of clear-sky periods in a 24-h diurnal cycle $\left(f_{c s}\right)$. The first data column and row list the number of days identified as only synoptically undisturbed and only clear-sky, respectively

\begin{tabular}{lrrrrr}
\hline & \multicolumn{1}{c}{$f_{C S}$} & & & & \\
\cline { 2 - 6 } & - & 90 & 80 & & 60 \\
\hline$\delta Z / L$ & & 182 & 257 & 339 & 431 \\
- & & 54 & 71 & 86 & 101 \\
$4 \times 10^{-5}$ & 188 & 81 & 105 & 128 & 147 \\
$5 \times 10^{-5}$ & 301 & & & & \\
\hline
\end{tabular}

the number of identified VWDs is, however, very similar to the number identified for the VF0 site, with 57 VWDs compared to 54 VWDs. A CSI value is also calculated operationally for the ARAD network stations based on MP00 (Olefs et al. 2016). Therefore, the number of clear-sky days and VWDs was also determined based on MP00 for this dataset (Table 2). With the same multiplication factor of 1.07 a slightly higher number of clear-sky days and the same number of VWDs is again identified compared to the VF0 site, with 192 clear-sky days and 53 VWDs compared to 180 clear-sky days and 53 VWDs. Without the additional multiplication factor, the number of identified clear-sky days is, however, only seven. This shows again that only very low $\epsilon_{A}$ are identified as clear sky when unmodified parametrizations are used for $\epsilon$, so that only a small fraction of clear-sky conditions is captured.

Several other studies have based the identification of clear-sky days on solar incoming radiation, which has the disadvantage that it works only during daytime. For example, Giovannini et al. (2017) defined a clear-sky day if the daily solar radiation exceeds $50 \%$ of the maximum daily solar radiation during that month. Whiteman et al. (1999) compared the daily incoming solar radiation to the extraterrestrial radiation, defining a clear-sky or partly cloudy day if the observed radiation exceeds $64 \%$ of the extraterrestrial radiation. This threshold value depends on the altitude but also changes throughout the year, with larger fractions of the extraterrestrial radiation reached in summer (not shown). Martínez et al. (2008) avoided this seasonal effect by normalizing the difference between the daily averaged solar radiation and the daily averaged extra-terrestrial radiation by the latter, defining a clear-sky day if this normalized difference $\leqslant 0.4$, while Conangla et al. (2018) used a somewhat lower threshold of 0.3 . Keeping in mind that these classification schemes and particularly the threshold values may be more (Whiteman et al. 1999) or less (Giovannini et al. 2017) site-dependent, they were applied to the VF0 site for comparison. The algorithm by Giovannini et al. (2017) yielded 823 clear-sky days, Martínez et al. (2008) 449 days, and Whiteman et al. (1999) 591 days. Whiteman et al. (1999) argues that their classification selects clear-sky and partly cloudy days. Similarly, it is clear that the criterion of Giovannini et al. (2017) selects partly cloudy days as well, as the clear-sky daily solar radiation does not change by $50 \%$ within a month. The identification method presented above, however, is designed to select only the most ideal conditions, including cloud-free conditions during $90 \%$ of a full $24-\mathrm{h}$ diurnal cycle (i.e., the fraction of clear-sky conditions $f_{c s}=90 \%$ ). Relaxing this $90 \%$ threshold, yields a continuously larger number of VWDs (Table 3). Using $f_{c s}=60 \%$, that is, including partly cloudy conditions, a similar number of clear-sky days is identified as with the above methods from other studies. 


\section{Valley-Wind Days}

Taking both criteria together, that is, synoptically undisturbed days and clear-sky days, a total of 54 VWDs are identified, with 12-16 days per year. The small number of VWDs is also a result of the small overlap between the 188 synoptically undisturbed days and the 182 clear-sky days (Table 3 ) so that only about $30 \%$ of the clear-sky days are also synoptically undisturbed and vice-versa (Fig. 3). While the number of clear-sky days increases when the fraction for clear-sky periods of $90 \%$ is relaxed, the resulting increase in the number of VWDs remains small, since the fraction of identified clear-sky days that are simultaneously identified as synoptically undisturbed decreases (Fig. 3). Similarly relaxing the threshold on the geopotential-height gradient to $5 \times 10^{-5}$ leads to an increase in the number of VWDs (Table 3), mainly because the fraction of clear-sky days identified as synoptically undisturbed increases from about $30 \%$ to about $45 \%$, while the fraction of synoptically undisturbed days identified as clear-sky days does not change much (Fig. 3).

The presented method is thus fairly restrictive so that only about 15 VWDs are identified per year, which is less than 5\%. Vergeiner and Dreiseitl (1987) used a criterion based on a twice-daily wind transition in Innsbruck to identify VWDs in the Inn Valley and found that a valley-wind system formed on $30 \%$ of all days. Whiteman (1990) lists similar numbers from other studies, with VWDs on about $40 \%$ of the days in a dry valley in the California coastal range and the Brush Creek Valley, Colorado. Saigger (2017, unpublished BS thesis), however, developed an automatic VWD detection algorithm for Innsbruck based on the criteria of Vergeiner and Dreiseitl (1987) and found also a lower number of VWDs for 2015-2016, with 19\%. Vergeiner and Dreiseitl (1987) also identified days with weak pressure gradients on $28 \%$ of all days, with a valley-wind circulation forming on only $43 \%$ of these weak-pressure-gradient days. Their results indicate that a valley-wind circulation does not necessarily form on synoptically undisturbed days. This also agrees with the findings presented above in that only a fraction of the synoptically undisturbed days (corresponding to the weak pressure-gradient days by Vergeiner and Dreiseitl (1987)) are also clear-sky days and thus expected to develop a more or less undisturbed valley-wind circulation. The number of synoptically undisturbed days is somewhat lower than the $28 \%$ weak pressure-gradient days by Vergeiner and Dreiseitl (1987), with about $13 \%$, even with a relaxed threshold value for the geopotential-height gradient of $5 \times 10^{-5}$ (about 21\%). Vergeiner and Dreiseitl (1987) also show that a valley-wind circulation can form even if the conditions are not entirely synoptically undisturbed, which may partly explain why our method yields relatively few VWDs, since it is not based on the valley-wind circulation and a valley-wind circulation may thus be present even on some of the less perfect days.

To record only days with a pure thermally-driven valley-wind circulation, foehn days are excluded using the foehn diagnosis of Plavcan et al. (2014), resulting in a total of 46 VWDs, with 9-13 days per year. It has to be noted that the foehn days have been identified based on observations in Innsbruck and in Ellbögen in the Wipp Valley, south of Innsbruck. Figure 5a shows the distribution of the 30 -min averaged wind direction at the valley floor between 2014 and 2017. The flow is generally aligned in the direction of the valley axis independent of the synoptic situation, as the flow is channeled in the valley. There is a higher frequency for flow from the east-north-east $\left(\approx 60-90^{\circ}\right)$ than from the west-south-west $\left(\approx 240^{\circ}\right)$, but the wind direction is mostly independent of the time of day, with flow from either direction occurring at any time of the day. When looking only at data from the identified VWDs, the wind direction is more frequently from the west-south-west, that is, down-valley (Fig. 5b). There is also a distinct diurnal cycle, with the flow almost exclusively down-valley before 


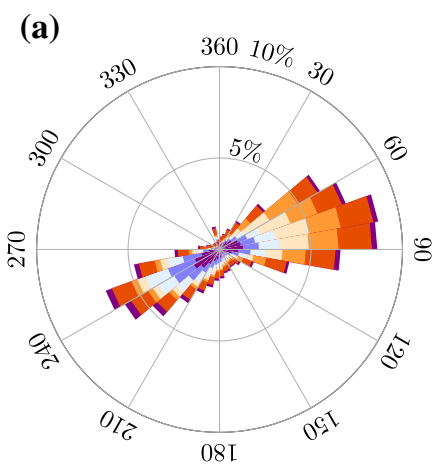

(b)

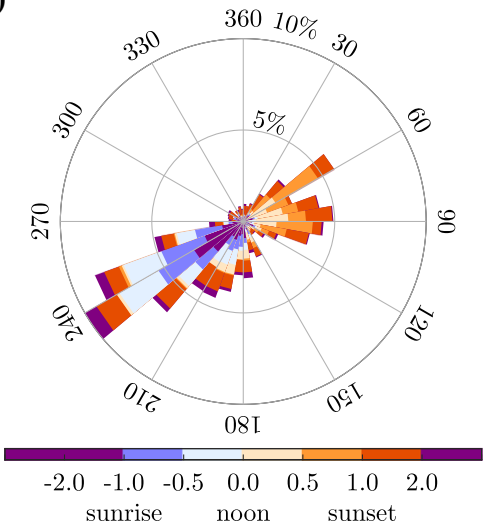

Fig. 5 Wind-direction distribution at the VF0 site for a all days from 2014 to 2017 and $\mathbf{b}$ only VWDs. The colour coding indicates the local time of day with respect to astronomical sunrise and sunset

solar noon and similarly, almost exclusively up-valley between noon and sunset, with the wind direction changing back to down-valley sometime after sunset. The wind field thus shows the twice daily flow reversal on the identified VWDs characteristic of a valley-wind circulation (e.g., Zardi and Whiteman 2012), changing from down-valley to up-valley around noon and vice versa in the evening.

To illustrate the average diurnal cycle of the valley-wind circulation, mean diurnal cycles of wind speed and wind direction at the VF0 site during 38 VWDs are shown in Fig. 6b, c. The lower number of averaged diurnal cycles compared to the total number of identified VWDs is a result of missing data. Short data gaps of two hours or less were filled by linear interpolation before averaging, but days with longer gaps were excluded from the analysis. In addition, Fig. 6a shows the pressure difference between Innsbruck and Kufstein, approximately $60 \mathrm{~km}$ to the east of the VF0 site. The pressure data are from the respective operational weather stations of the Austrian weather service (Zentralanstalt für Meteorologie und Geodynamik ZAMG) and the pressure from Kufstein was first reduced hydrostatically to the altitude of Innsbruck before calculating horizontal differences, using the mean temperature between Innsbruck and Kufstein. The exact VWDs used for calculating mean diurnal cycles of windspeed and pressure differences differ since both datasets are incomplete and data on several of the identified VWDs are missing.

During night-time and in the morning before sunrise, mean wind speeds are low and the wind direction is south-westerly, that is, down-valley, in agreement with the positive pressure difference between Innsbruck and Kufstein. After sunrise, the pressure difference decreases and wind speed increases, but the wind direction remains down-valley until approximately noon. Around noon, the flow reverses to an up-valley direction together with a change in the sign of the pressure difference. The wind speed can drop to almost zero during the flow reversal, but increases again afterwards. The diurnal cycle of wind speed thus shows two maxima, a first maximum during the down-valley flow in the morning after sunrise and a second maximum during the up-valley flow in the afternoon. The two maxima in the alongvalley wind were also shown by Dreiseitl et al. (1980) in their Fig. 10 (reproduced in Egger 2003). We hypothesize that the morning maximum is caused by the downward mixing of momentum in the growing mixed layer. 

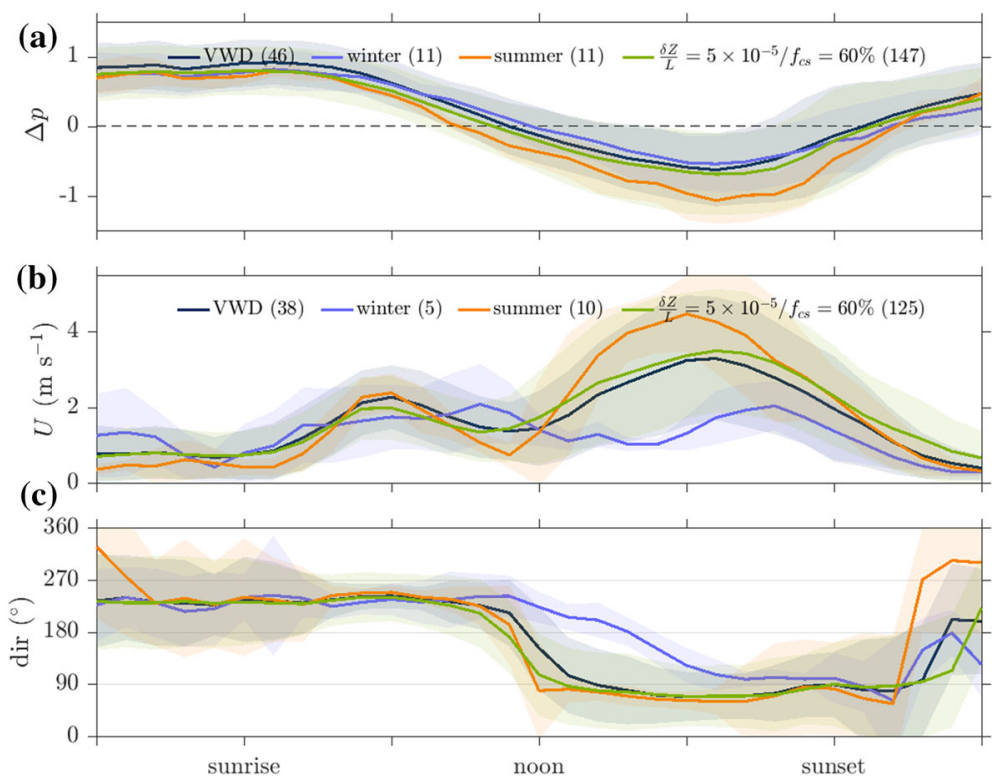

Fig. 6 Mean diurnal cycle of, a the pressure difference between Innsbruck and Kufstein, b wind speed, and c wind direction at the VF0 site. The pressure from Kufstein was reduced to the elevation of Innsbruck before calculating differences. The blue and orange lines are for VWDs in winter and summer, respectively, and the green line is for VWDs identified by using modified threshold values (see text). Shading indicates the standard deviation. The numbers in parentheses indicate the number of days used for averaging, with the same number of days for wind speed and wind direction

Wind speed starts to decrease again in the afternoon when the along-valley pressure difference weakens, but the flow does not reverse to a down-valley direction until after sunset. A delay of several hours between sunrise and the morning wind reversal and sunset and the evening wind reversal is typical (Conangla et al. 2018), since the entire valley atmosphere has to warm or cool for the valley-plain pressure gradient to reverse (Zardi and Whiteman 2012). The timing of the reversal thus depends on the size and shape of the valley, with a morning transition from down-valley to up-valley flow at almost precisely solar noon in the Inn Valley (Fig. 6c).

Diurnal cycles of wind speed and wind direction for VWDs based on more relaxed thresholds for the geopotential-height gradient and fraction of clear-sky periods per day still show a very similar valley-wind circulation on average, with somewhat higher standard deviations (Fig. 6). This is not too surprising since even partly cloudy days, for example, due to afternoon convection in summer, are still likely to be determined mainly by a valley-wind circulation.

The majority of VWDs are found in autumn (September-November), with 19 days, that is, almost four times as many as during spring (March-May) with only 5 VWDs. Winter (December-February) and summer (June-August) are somewhere in-between, with 11 identified VWDs each. While conditions for a thermally-driven valley-wind circulation thus occur throughout the year although not evenly distributed, the resulting valley-wind circulation differs significantly in strength and timing between summer and winter (Fig. 6) as a result of shorter days and thus reduced irradiation in winter. In winter, the period with higher pressure down-valley of Innsbruck and an up-valley flow is shorter than in summer, which was also found by Vergeiner and Dreiseitl (1987), who, however, looked at absolute times, 
(a)

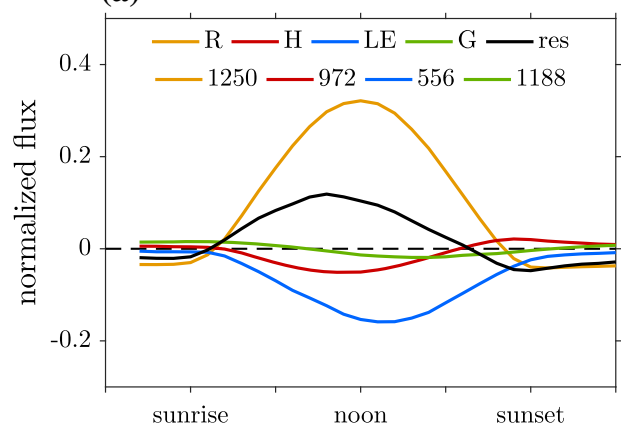

(b)

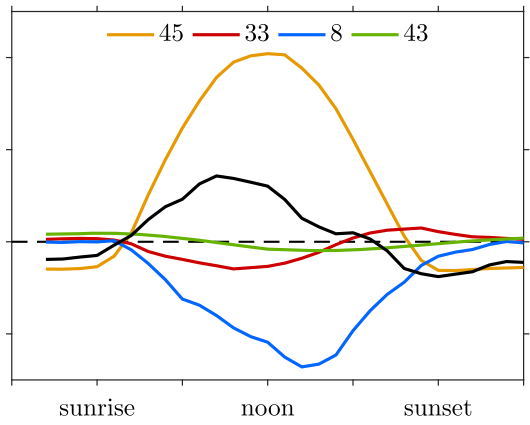

Fig. 7 Mean energy balance for, a all complete days between 2014 and 2017, and b only VWDs: R-net radiation, $\mathrm{H}$ - sensible heat flux, LE - latent heat flux, G-ground heat flux, and res — residual. The fluxes are normalized by the calculated daily maximum solar irradiation at the top of the atmosphere at the VF0 site. The numbers in the legend show the respective numbers of complete days available for averaging

which further enhance this effect. The shorter up-valley-flow period is mainly a result of a later transition from down-valley to up-valley flow, whereas the evening transition occurs on average at a similar time as in summer. In addition, the diurnal cycle in wind speed is much more pronounced in summer, with the two wind-speed maxima somewhat delayed in winter and particularly the afternoon maximum strongly reduced in strength.

Differences in the mean surface energy balance at the VF0 site between all days from 2014 to 2017 and only VWDs are highlighted in Fig. 7. Since clear-sky conditions are one criterion for the identification of VWDs, the magnitude of net radiation is expected to be larger during VWDs. The increase in net radiation after sunrise is indeed steeper for the VWDs, and it reaches an approximately $30 \%$ higher peak at noon. Reduced incoming longwave radiation leads to correspondingly more negative net radiation for VWDs during night-time. The gain in net radiation during VWDs is mostly balanced by a loss in latent heat flux at this site during daytime, which is about twice as large during VWDs than the overall mean. The sensible heat flux and the ground heat flux are much smaller in magnitude than the latent heat flux and show little difference between VWDs and the overall mean. Since only nine days with complete latent heat flux data were available for averaging compared to a much larger number for the other components, the average budgets were also calculated for just these nine days. The results are very similar to Fig. 7b, suggesting that the shown averaged energy balance for VWDs is robust. During night-time, the larger negative net radiation during VWDs compared to the overall average is not balanced by a similar increase in the latent heat flux, so that the residual is much larger during these days.

\section{Concluding Remarks}

A method has been presented that identifies valley-wind days (VWDs) in the Inn Valley, Austria, which requires relatively few measured parameters (longwave incoming radiation, air temperature, and humidity). Since the method is based on the identification of synoptically undisturbed, clear-sky conditions rather than the wind circulation, it is also applicable to other thermally-driven circulation systems, such as land-sea breezes. By definition, the method does not identify days with a valley-wind circulation but rather days with the conditions (i.e., clear-sky and weak large-scale pressure gradient) when thermally-driven flows are expected 
to dominate the wind field. Even though a twice daily flow reversal is characteristic for thermally-driven flows, including valley winds (Zardi and Whiteman 2012), down-valley winds are the dominant feature during the winter season (Vergeiner and Dreiseitl 1987) and even in the possible absence of a transition to a daytime up-valley flow during winter days, a persistent down-valley flow can still be called a thermally-driven valley wind. The proposed method therefore does not make any a priori assumptions about the diurnal cycle of the valley-wind circulation.

Synoptically undisturbed conditions are identified using a threshold value for the ERA Interim geopotential-height gradient at $700 \mathrm{hPa}$, that is, above the surrounding mountain ridges. The evaluated gradients are thus representative of the large-scale pressure gradient at the measurement site. Vergeiner and Dreiseitl (1987) manually identified days with weak pressure gradients in their classification. Here we defined a threshold value based on the definition of extra-tropical synoptic pressure disturbances (Holton and Hakim 2013) and the distribution of the geopotential-height gradients at the location over a few years. Clear-sky conditions are identified using a clear-sky index, which is the ratio between actual atmospheric emissivity calculated from longwave incoming radiation and parametrized clear-sky emissivity. Using a clear-sky index based on longwave radiation has the advantage that it works equally well during day and night in contrast to the more commonly used criteria based on solar incoming radiation. Konzelmann et al. (1994), however, mention that longwave incoming radiation is relatively insensitive to high clouds, which implies that the identification of clear-sky conditions based on longwave incoming radiation may thus fail to recognize high cirrus clouds.

The proposed method is not site-independent, since the appropriate parametrization for clear-sky emissivity varies from site to site and has to be first determined, for which a relatively long dataset should be used. By testing different parametrizations for the Inn Valley, it was shown that while some of the parametrizations clearly performed worse than others, suggesting their inappropriateness for this location, other parametrizations performed similarly well. While we eventually selected a parametrization due to Prata (1996), a different parametrization of Marty and Philipona (2000) gave very similar results in terms of identifying clear-sky days and thus VWDs. The need for a multi-month radiation dataset clearly limits the application of the proposed method for short-term field campaigns, unless representative routine long-term observations of longwave radiation, temperature, and humidity are available from a nearby station.

The identification of clear-sky conditions in our example relies entirely on observations at a single site at the valley floor. Days with scattered clouds over the surrounding mountains can thus be classified as clear-sky days, as is indeed the case for some of our VWDs. A comparison between two sites that are both located in the Inn Valley and are approximately $20 \mathrm{~km}$ apart also shows small differences in the identified days. The presence of scattered clouds, however, does not necessarily prevent the formation of a valley-wind circulation. Depending on the application and on the availability of measurements at multiple sites, the clear-sky index could, however, also be evaluated at multiple sites within a valley. In addition, other processes that occur during synoptically undisturbed, clear-sky conditions may still disturb the valley-wind circulation on the identified VWDs. For example, in the Inn Valley, foehn is present during some of the identified VWDs, which had to be excluded separately through the use of an additional filter.

The presented method is also sensitive to the selected thresholds, for example, for the geopotential-height gradient to identify synoptically undisturbed conditions, and to the required fraction of clear-sky periods within a day. The thresholds used here are fairly restrictive, resulting in a relatively small number of VWDs. These thresholds were selected to 
identify only the most ideal days for thermally driven winds. Relaxing the thresholds yields a larger number of VWDs, which include, for example, more partly cloudy days, which may, however, still develop pronounced thermal circulations. The selection of these thresholds thus also depends on the objectives.

Acknowledgements Open access funding provided by University of Innsbruck and Medical University of Innsbruck. We thank all the colleagues, students, and particularly the technicians at ACINN whose contributions are vital to collecting high-quality data in the i-Box project. The i-Box infrastructure has been established through funding by the University of Innsbruck. We also thank three reviewers for their very helpful comments.

Open Access This article is distributed under the terms of the Creative Commons Attribution 4.0 International License (http://creativecommons.org/licenses/by/4.0/), which permits unrestricted use, distribution, and reproduction in any medium, provided you give appropriate credit to the original author(s) and the source, provide a link to the Creative Commons license, and indicate if changes were made.

\section{References}

Ångström A (1916) A study of the radiation of the atmosphere. Smithsonian Misc Collect 65:2354

Brutsaert W (1975) On a derivable formula for long-wave radiation from clear skies. Water Resour Res 11:742-744

Conangla L, Cuxart J, Jiménez MA, Martínez-Villagrasa D, Miró JR, Tabarelli D, Zardi D (2018) Cold-air pool evolution in a wide Pyrenean valley. Int J Climatol 38:2852-2865

Dee DP, Uppala SM, Simmons AJ, Berrisford P, Poli P, Kobayashi S, Andrae U, Balmaseda MA, Balsamo G, Bauer P, Bechtold P, Beljaars ACM, van de Berg L, Bidlot J, Bormann N, Delsol C, Dragani R, Fuentes M, Geer AJ, Haimberger L, Healy SB, Hersbach H, Hólm EV, Isaksen L, Kållberg P, Köhler M, Matricardi M, McNally AP, Monge-Sanz BM, Morcrette J-J, Park B-K, Peubey C, de Rosnay P, Tavolato C, Thépaut J-N, Vitart F (2011) The ERA-Interim reanalysis: configuration and performance of the data assimilation system. Q J R Meteorol Soc 137:553-597

Dilley AC, O'Brien DM (1998) Estimating downward clear sky long-wave irradiance at the surface from screen temperature and precipitable water. Q J R Meteorol Soc 124:1391-1401

Dreiseitl E, Feichter H, Pichler H, Steinacker R, Vergeiner I (1980) Windregimes an der Gabelung zweier Alpentäler. Arch Meteorol Geophys Bioclimatol B28:257-275

Egger J (2003) Valley winds. In: Holton JR (ed) Encyclopedia of atmospheric sciences. Elsevier Academic Press, Cambridge, pp 2481-2490

Giovannini L, Laiti L, Serafin S, Zardi D (2017) The thermally driven diurnal wind systems of the Adige Valley in the Italian Alps. Q J R Meteorol Soc 143:2389-2402

Goger B, Rotach MW, Gohm A, Fuhrer O, Stiperski I, Holtslag AAM (2018) The impact of three-dimensional effects on the simulation of turbulence kinetic energy structure in a major Alpine valley. Boundary-Layer Meteorol 168:1-27

Holton JR, Hakim GJ (2013) An introduction to dynamic meteorology. Academic Press, Cambridge

Idso SB (1981) A set of equations for full spectrum and 8- to $14-\mu \mathrm{m}$ and 10.5 - to $12-\mu \mathrm{m}$ thermal radiation from cloudless skies. Water Resour Res 17:295-304

Idso SB, Jackson RD (1969) Thermal radiation from the atmosphere. J Geophys Res 74:5397-5403

Konzelmann T, van de Wal RSW, Greuell W, Bintanja R, Henneken EAC, Abe-Ouchi A (1994) Parameterization of global and longwave incoming radiation for the Greenland ice sheet. Global Planet Change 9:143-164

Lehner M, Rotach MW (2018) Current challenges in understanding and predicting transport and exchange in the atmosphere over mountainous terrain. Atmos 9:271

Martínez D, Cuxart J, Cunillera J (2008) Conditioned climatology for stably stratified nights in the Lleida area. Tethys J Weather Climat West Mediterr 5:13-24

Marty C, Philipona R (2000) The clear-sky index to separate clear-sky from cloudy-sky situations in climate research. Geophys Res Lett 27:2649-2652

Matzinger N, Andretta M, van Gorsel E, Vogt R, Ohmura A, Rotach MW (2003) Surface radiation budget in an Alpine valley. Q J R Meteorol Soc 129:877-895

Niemelä S, Räisänen P, Savijärvi H (2001) Comparison of surface radiative flux parameterizations. Part I: longwave radiation. Atmos Res 58:1-18 
Olefs M, Baumgartner DJ, Obleitner F, Bichler C, Foelsche U, Pietsch H, Rieder HE, Weihs P, Geyer F, Haiden T, Schöner W (2016) The Austrian radiation monitoring network ARAD—best practice and added value. Atmos Meas Tech 9:1513-1531

Plavcan D, Mayr GJ, Zeileis A (2014) Automatic and probabilistic foehn diagnosis with a statistical mixture model. J Appl Meteorol Clim 53:652-659

Prata AJ (1996) A new long-wave formula for estimating downward clear-sky radiation at the surface. Q J R Meteorol Soc 122:1127-1151

Rotach MW, Stiperski I, Fuhrer O, Goger B, Gohm A, Obleitner F, Rau G, Sfyri E, Vergeiner J (2017) Investigating exchange processes over complex topography-the Innsbruck Box (i-Box). Bull Am Meteorol Soc 98:787-805

Satterlund DR (1979) An improved equation for estimating long-wave radiation from the atmosphere. Water Resour Res 15:1649-1650

Sedlar J, Hock R (2009) Testing longwave radiation parameterizations under clear and overcast skies at Storglacären, Sweden. Cryos 3:75-84

Serafin S, Adler B, Cuxart J, De Wekker SFJ, Gohm A, Grisogono B, Kalthoff N, Kirshbaum DJ, Rotach MW, Schmidli J, Stiperski I, Vecenaj Z, Zardi D (2018) Exchange processes in the atmospheric boundary layer over mountainous terrain. Atmos 9:102

Swinbank WC (1963) Long-wave radiation from clear skies. Q J R Meteorol Soc 89:339-348

Vergeiner I, Dreiseitl E (1987) Valley winds and slope winds - observations and elementary thoughts. Meteorol Atmos Phys 36:264-286

Whiteman CD (1990) Observations of thermally developed wind systems in mountainous terrain. In: Blumen W (ed) Atmospheric processes over complex terrain, vol 23. Monogr Amer Meteorol Soc, Boston, pp 5-42

Whiteman CD, Bian X, Sutherland JL (1999) Wintertime surface wind patterns in the Colorado River Valley. J Appl Meteorol 38:1118-1130

Zardi D, Whiteman CD (2012) Diurnal mountain wind systems. In: Chow FK, De Wekker SFJ, Snyder B (eds) Mountain weather research and forecasting. Springer, Berlin

Publisher's Note Springer Nature remains neutral with regard to jurisdictional claims in published maps and institutional affiliations. 